\title{
Trade pact blow for innovative drug developers
}

Biopharma companies and their lobbying groups were stung in early October when a historic trade pact proposal failed to include 12 years of data exclusivity for biologic medicines. Instead, the Trans-Pacific Partnership (TPP), if ratified by all Pacific Rim member nations, will offer five years' data exclusivity, with potential mechanisms to extend that to eight years, according to the final document released for public review November 5 .

The TPP deal is a trade agreement between Australia, Brunei Darussalam, Canada, Chile, Japan, Malaysia, Mexico, New Zealand, Peru, Singapore, the United States and Vietnam. It lays out plans for handling trade in many different areas, including therapeutics. Negotiations began in 2009 , and ratification by the US Congress is expected in 2016 . The TPP agreement carries considerable weight for the biopharma industry, as trade in these nations accounts for more than $40 \%$ of global GDP.

The five-year exclusivity period for biologics has thus been greeted with dismay by industry stakeholders, who feel that this is not enough to protect innovator biologics from early competition. A statement from Biotech Industry Organization president and CEO Jim Greenwood said the group "strongly believes that 12 years of data exclusivity is a prerequisite" for attracting the level of investment necessary to develop new biologic medicines and encourage innovation. The 12-year period that was codified into US law as part of the Patient Protection and Affordable Care Act (ACA) in 2010 (Nat. Biotechnol. 28, $385-386,2010$ ) will remain in force in the US; and because the TPP only sets a floor, other nations could similarly choose to implement longer data exclusivity periods beyond what is called for by the recent agreement.

$\mathrm{BIO}$ argues the shorter length of protection in the TPP will "chill global investment" and slow the development of new medicines. A statement from Pharmaceutical Research and Manufacturers Association of America (PhRMA) president and CEO John Castellani said, "It appears that the Ministers missed the opportunity to encourage innovation that will lead to more important, life-saving medicines that would improve patients' lives."

But some analysts suggest that 12 years was a surprisingly high bar in the first place. Ramsey Baghdadi, a founder of the Washington, DC-based healthcare policy analysis firm Prevision Policy, calls the ACA biologics data exclusivity provision the "key victory" for branded biologics stakeholders. Industry failed to get what it wanted this time, "but I think they did fine," says Baghdadi. Indeed few stakeholders thought the 12-year ACA exclusivity proposal would stand; rather it was viewed at the time as an opening gambit that "would be cut back a bit," says William James, a Washington, DC-based partner in the IP litigation group of law firm Goodwin Procter, who represents clients from both the branded biologics and biosimilars sides of the debate. "It's fair to say the branded biopharma industry has been happy with it."

Nevertheless, BIO has expressed its disappointment over a "remarkably short-sighted" failure to agree to a longer exclusivity period in the TPP. Biologics data exclusivity was one of the "most challenging issues" in negotiating the TPP agreement, US trade representative Michael Froman acknowledged during a trade ministers' press conference in Atlanta, on October 5, the day TPP negotiation was concluded. He called the five-to-eight years' exclusivity outcome "strong and balanced," one that weighed both incentives for drug development and access to life-saving therapies.

The final text of the TPP was submitted to US Congress in October for a 30-day behindclosed-doors review, which will be followed by a 60-day public comment period, during which the biopharma industry interest groups may have more to say about the specifics of the deal. Following that period, the US International Trade Commission will perform an economic analysis, after which Congress will have 90 days to approve the TPP (under socalled "fast-track" authority granted by Congress earlier in 2015, legislators must vote on the deal as is, without amendments or additional delays).

In the meantime, nonprofit organizations including Doctors Without Borders and politicians including US Democratic presidential hopefuls Hillary Clinton and Bernie Sanders have blasted the TPP deal for, among other reasons, being too pharma friendly, predicting that it will hurt patients and healthcare providers in developing nations. The TPP does appear to be a win for biosimilar manufacturers, who may eventually access small Pacific-nation markets earlier than they would have otherwise.

But the fact that stakeholders on opposite sides of the debate have condemned the agreement may underscore its evenhandedness. "I think you could make the case that it's not a terrible compromise," says Goodwin Procter's James.

Chris Morrison Yardley, Pennsylvania 